\title{
PERIPHERAL NERVE CONDUCTION IN DIABETIC NEUROPATHY ${ }^{1}$
}

\author{
R. W. GILLIATT and R. G. WILLISON ${ }^{2}$ \\ From the Institute of Clinical Research, the Middlesex Hospital Medical School, and the Department \\ of Applied Electrophysiology, the National Hospital, Queen Square, London
}

The estimation of motor nerve conduction velocity and the direct recording of nerve action potentials are now well established electrodiagnostic procedures, and this paper is concerned with their application to patients with diabetic neuropathy.

It is already known that in these patients motor conduction velocity may become slow (FerrariForcade, Temesio, and Gomensoro, 1960; Mulder, Lambert, Bastron, and Sprague, 1961; Skillman, Johnson, Hamwi, and Driskill, 1961) and that nerve action potentials may be lost (Gilliatt, Goodman, and Willison, 1961), these changes being similar to those found in other forms of peripheral neuropathy. For the present paper we have selected a small number of diabetic patients who have been extensively investigated, with the object of relating the electrical findings to the particular clinical features of individual cases.

\section{METHODS}

The methods used for estimating motor conduction velocity and for recording nerve action potentials have been fully described in previous publications (Gilliatt and Sears, 1958; Thomas, Sears, and Gilliatt, 1959; Gilliatt et al., 1961). For the measurement of the latency of the knee jerk a special patellar hammer was constructed containing a micro-switch to trigger the oscilloscope; the electrical response of the quadriceps muscle was then recorded through surface electrodes as described by Malcolm (1951) and by Bergamini and Sibour (1960).

\section{RESULTS}

SENSORY NEUROPATHY AFFECTING THE LOWER LIMBS It is generally accepted that the most common form of diabetic neuropathy is that in which sensory disturbances occur in the lower limbs without muscular wasting or weakness but with depression or loss of tendon reflexes. In such cases the sensory disturbance is often mainly subjective, pain and paraesthesiae being present without conspicuous sensory loss on clinical testing. We have examined five such

${ }^{1}$ Based on a paper read to the Association of British Neurologists in April 1961

${ }^{2}$ Clinical research fellow, M.R.C. patients, in all of whom the presenting complaint was of pain in the legs or feet. None of the patients showed significant muscular wasting or weakness in the lower limbs but reflex and sensory changes were present in all of them. Clinical details are summarized in Table I, from which it can be seen that the

\section{TABLE I}

CLINICAL. FINDINGS IN PATIENTS WITH SENSORY NEUROPATHY

\begin{tabular}{|c|c|c|c|c|c|c|c|c|c|}
\hline \multirow[t]{2}{*}{ Case } & \multirow[t]{2}{*}{ Age } & \multirow[t]{2}{*}{$K J$} & \multirow[t]{2}{*}{$\boldsymbol{A J}$} & \multicolumn{2}{|c|}{ Vibration } & \multicolumn{2}{|c|}{ Light Touch } & \multicolumn{2}{|c|}{ Pin Prick } \\
\hline & & & & Shin & Foot & Shin & Foot & Shin & Foot \\
\hline 1 & 72 & + & + & \pm & $\mathbf{0}$ & + & \pm & + & \pm \\
\hline 2 & 54 & + & \pm & \pm & $\mathbf{0}$ & + & + & + & + \\
\hline 3 & 47 & + & \pm & $\bar{t}$ & 0 & \pm & \pm & \pm & \pm \\
\hline 4 & 53 & 0 & 0 & \pm & 0 & + & \pm & + & \pm \\
\hline 5 & 36 & \pm & 0 & \pm & $\mathbf{0}$ & \pm & \pm & \pm & $\overline{0}$ \\
\hline
\end{tabular}

most constant feature was loss of vibration sensation in the feet. Other forms of sensation were less uniformly affected and depression of tendon reflexes was also variable.

As an illustrative example, Case 3 is described in detail.

Case 3. Mr. G. S. (M.H. K31441), a building contractor aged 47, was admitted to the Middlesex Hospital under the care of Dr. J. D. N. Nabarro in March 1958. Diabetes had been discovered two years previously and had been treated by diet and tolbutamide. For a year before admission the patient had suffered increasingly from burning pain in the feet which became sufficiently severe to prevent him working and to interfere with sleep. Neurological examination revealed no muscular wasting or weakness, and the deep reflexes were generally brisk, with the exception of the ankle jerks which were reduced. The plantar responses were flexor. There was some subjective change in the sensations aroused by touch and pin prick over the feet and lower shins, touches producing a tingling sensation and pin prick having a peculiarly unpleasant quality. A tuning fork ( $128 \mathrm{c} / \mathrm{s})$ was appreciated on the shins but not on the feet or toes. Joint sensation in the toes was normal.

In all five patients a standard procedure was used for the examination of nerve conduction. Velocity was estimated in the motor nerve fibres to the extensor digitorum brevis by stimulation at the 
ankle and at the head of the fibula, muscle action potentials being recorded with a concentric needle electrode. For the examination of nerve action potentials the anterior tibial nerve was stimulated at the ankle with recording needles inserted close to the lateral popliteal nerve at the head of the fibula. The results of these procedures in the five patients are shown in Table II, from which it can be seen that

\section{TABLE II}

CONDUCTION IN LATERAL POPLITEAL NERVE IN PATIENTS WITH SENSORY NEUROPATHY

\begin{tabular}{|c|c|c|c|}
\hline \multirow[t]{2}{*}{ Case } & \multirow{2}{*}{$\begin{array}{l}\text { Motor } \\
\text { Velocity } \\
(m . / \text { sec. })\end{array}$} & \multicolumn{2}{|c|}{ Nerve Action Potential } \\
\hline & & $\begin{array}{l}\text { Velocity } \\
\text { to Peak } \\
(\mathrm{m} . / \mathrm{sec} .)\end{array}$ & $\begin{array}{l}\text { Amplitude } \\
(\mu V)\end{array}$ \\
\hline $\begin{array}{l}1 \\
2\end{array}$ & $\begin{array}{l}33.0 \\
39.0\end{array}$ & $\begin{array}{l}\text { Absent } \\
33 \\
\text { approximately }\end{array}$ & $\begin{array}{l}\text { Absent } \\
1.0\end{array}$ \\
\hline $\begin{array}{l}3 \\
4 \\
5 \\
\text { Normal range }\end{array}$ & $\begin{array}{l}34 \cdot 0 \\
18 \cdot 5 \\
15 \cdot 2 \\
35 \cdot 6-63 \cdot 5^{1}\end{array}$ & $\begin{array}{l}\text { Absent } \\
\text { Absent } \\
\text { Absent } \\
33 \cdot 8-51 \cdot 8^{2}\end{array}$ & $\begin{array}{l}\text { Absent } \\
\text { Absent } \\
\text { Absent } \\
2-15 \cdot 5^{2}\end{array}$ \\
\hline
\end{tabular}

the most frequent finding was loss of the nerve action potential. A very small potential was present in Case 2; in the remaining four patients the nerve action potential was absent. Motor velocity was less constantly affected. There was one result within the normal range and two just below the lower limit of normal; in only two out of the five patients was motor velocity substantially decreased. In these last two patients the number of motor units in the extensor digitorum brevis which could be activated voluntarily was also reduced, although no definite weakness of dorsiflexion of the toes was demonstrated on clinical testing. This illustrates the difficulty of demonstrating weakness of the extensor digitorum brevis by ordinary clinical examination when power is fully preserved in the long extensors of the toes.

In this group of patients it is clear that the examination of nerve action potentials was a much more sensitive test of deranged function than the estimation of motor conduction velocity. While this may be partly explained on the basis of a predominantly sensory clinical picture, it must be remembered that in the estimation of motor velocity the figure obtained must necessarily apply to the fastest conducting fibres present; even if the majority of the nerve fibres are affected by a partial lesion, slowing will not be detected if a few normal fibres survive. On the other hand the nerve action potential depends upon the passage of a synchronous volley of impulses under the recording electrodes so that it is highly sensitive to temporal dispersion of impulses in different fibres. This probably explains the complete loss of the nerve action potential in Cases 1 and 3 in spite of motor conduction velocities close to the lower limit of the normal range.

MIXED MOTOR AND SENSORY NEUROPATHY We have investigated two patients with widespread muscular weakness and wasting in addition to sensory disturbance. In this context we hesitate to use the word 'polyneuropathy' as the term is usually taken to imply a symmetrical and peripheral disturbance, whereas in our two patients asymmetry and involvement of proximal muscles were conspicuous features. The relation of this group to the diabetic amyotrophy described by Garland (1955) will be discussed in a subsequent section.

Case 6. Mrs. F. K. (M.H. J19311) was first recognized to have diabetes in 1952 at the age of 54 . She was placed on a small daily dose of insulin. In 1955 she developed a right radial nerve palsy which recovered spontaneously within a few weeks, and in 1957 she was seen again with the complaint of pain and tingling in both hands, the patient's description being suggestive of the carpal tunnel syndrome. These symptoms also improved spontaneously after a few months, but during the following year the patient gradually developed generalized weakness of both arms and legs affecting proximal as well as distal muscles, so that she noticed difficulty in getting up from the sitting or kneeling position. The weakness was accompanied by numbness and tingling in the hands and feet. In January 1959 she was admitted to the Middlesex Hospital under
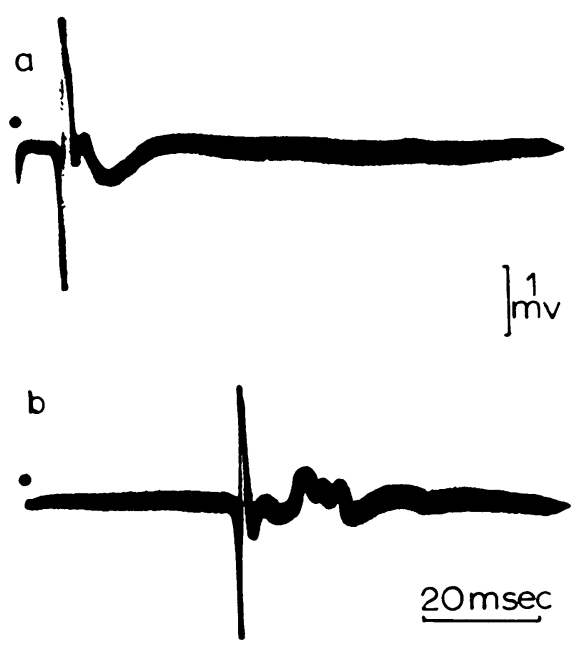

FIG. 1. Case 6. Action potentials recorded from the extensor digitorum brevis with stimulation of (a) the anterior tibial nerve at the ankle, and (b) the lateral popliteal nerve at the neck of the fibula. Stimulus at mark in each trace. Conduction velocity between knee and ankle, $11.4 \mathrm{~m} . / \mathrm{sec}$. 
the care of Dr. M. Kremer. In the upper limbs examination revealed wasting of the muscles of the shoulder girdles and of the small muscles of the hands; weakness was generalized and bilateral but was more marked on the right side than the left. In the lower limbs there was wasting and severe weakness of the quadriceps on both sides, with less severe weakness of other muscle groups; as in the arms the changes were more marked on the right side than the left. The tendon reflexes were depressed or absent. The plantar responses were flexor. Sensation was not severely affected but was subjectively altered over the right foot and over both hands. Joint sensation was also mildly impaired in the fingers and toes, and vibration sense lost in the legs. Lumbar puncture revealed a protein level of $110 \mathrm{mg} . / 100 \mathrm{ml}$. in the cerebrospinal fluid.

Electrical testing was carried out shortly after her admission to hospital and conduction velocity was found to be markedly reduced in the motor fibres to the small muscles of the hands and feet. A figure of $10.6 \mathrm{~m}$./ $/ \mathrm{sec}$. was obtained for the right median nerve in the forearm and a figure of $11.4 \mathrm{~m}$./ $\mathrm{sec}$. for the lateral popliteal nerve between knee and ankle. Illustrative tracings are shown in Fig. 1.

Case 7. Mr. B. C. (M.H. K75540), a business manager aged 62, first noticed weakness of the left leg in May 1960. The left knee would give way so that the patient fell, and later he became unable to straighten the left leg at all. Soon after the onset of weakness the patient noticed numbness of the soles of both feet and of the left leg below the knee. In August 1960 he was found to have glycosuria, and a provisional diagnosis of diabetic neuropathy was made.

The patient was admitted to the Middlesex Hospital under the care of Dr. Kremer in October 1960. Examination at that time revealed mild diabetic retinopathy but no other abnormality in the cranial nerves. There was slight weakness of the muscles of the shoulder girdles on both sides but no weakness in the arms or hands. The tendon reflexes in the arms were present but depressed. In the lower limbs weakness of hip flexion was present on both sides but was more marked on the left. The quadriceps muscle was severely wasted on the left, weakness being such that the patient was unable to straighten the left knee against gravity; muscle bulk and power were mildly reduced in the right quadriceps. The glutei and hamstrings were slightly affected on the left but not on the right. Although there was little wasting below the knee, the anterior tibial and peroneal muscles were weak on both sides, particularly on the left, with sparing of the calf muscles. The right knee jerk was depressed; the left knee jerk and both ankle jerks were absent. The plantar responses were flexor. Sensation was normal in the upper limbs. In the lower limbs there was subjective impairment of appreciation of both pin prick and cotton wool below the knee on the left and below the ankle on the right; there were occasional errors in appreciation of passive movements of the toes. Vibration sense was present in the legs but absent in the feet.

After the patient's admission to hospital the diagnosis of diabetes was confirmed by blood sugar estimation. Lumbar puncture revealed a protein level of $75 \mathrm{mg} . / 100$ $\mathrm{ml}$. in the cerebrospinal fluid.

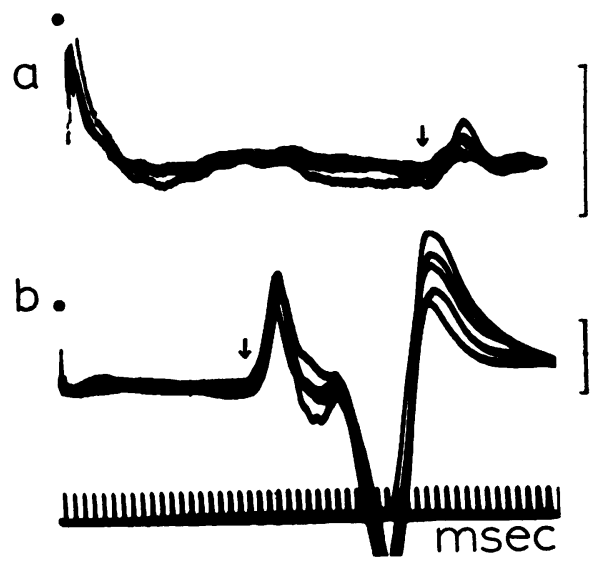

FIG. 2. Electrical response of quadriceps to patellar tap (a) in Case 7, and (b) in a healthy subject. Mechanical stimulus at mark and onset of reflex response at arrow in each case. Calibration $1 \mathrm{mV}$. Five traces superimposed.

Several electrical examinations were carried out while the patient was in hospital. Motor conduction velocity in the lateral popliteal nerve was $25 \mathrm{~m}$./sec. on the left and $33 \mathrm{~m} . / \mathrm{sec}$. on the right. No action potential could be recorded from the lateral popliteal nerve at the head of the fibula on stimulation of the anterior tibial nerve at the ankle. In contrast to these findings, conduction velocity in the motor fibres of the median nerve supplying the abductor pollicis brevis was normal $(51 \mathrm{~m}$. $/ \mathrm{sec}$.).

In the left leg the knee jerk was absent but on the right a reflex response could just be obtained with reinforcement. Accordingly the latency of the right knee jerk was recorded using a special reflex hammer to trigger the oscilloscope (see Methods); the reflex response was recorded through a pair of surface electrodes $4 \mathrm{~cm}$. apart, placed over the belly of the rectus femoris at the junction of its upper and middle thirds. Only a small electrical response was obtained (Fig. 2a), its latency being markedly increased (39 msec.). For comparison, records obtained in the same way from a healthy subject are shown in Fig. $2 \mathrm{~b}$, the latency of the normal reflex response being $19 \cdot 5$ msec.

In the first of these patients (Case 6) the small muscles of the hand were clinically affected and conduction in the motor fibres of the median nerve was markedly slowed. In the second patient power in the hands was fully preserved and motor conduction was normal. In both patients there was widespread weakness in the legs and conduction velocity in the lateral popliteal nerve was substantially reduced. Wasting and weakness were most marked in the proximal muscles of the lower limbs, and in Case 7 it was possible to demonstrate that the latency of the knee jerk was increased to nearly twice the normal figure although this was recorded on the less affected side. 
TABLE III

ELECTRICAL FINDINGS IN PATIENTS WITH ISOLATED NERVE LESIONS

\begin{tabular}{|c|c|c|}
\hline \multirow[t]{2}{*}{ Case } & \multirow[t]{2}{*}{ Clinical Diagnosis } & Electrical Findings \\
\hline & & Affected Nerve \\
\hline 8 & Right ulnar nerve lesion & $\begin{array}{l}\text { MCV slightly reduced } \\
\text { NAP absent }\end{array}$ \\
\hline 9 & Left ulnar nerve lesion & $\begin{array}{l}\text { Normal MCV } \\
\text { NAP of normal latency but reduced } \\
\text { amplitude }\end{array}$ \\
\hline 10 & $\begin{array}{l}\text { Right lateral popliteal nerve } \\
\text { lesion }\end{array}$ & $\begin{array}{l}\text { Normal MCV } \\
\text { NAP much reduced in amplitude, } \\
\text { latency slightly increased }\end{array}$ \\
\hline 11 & Right median nerve lesion & $\begin{array}{l}\text { Motor conduction slowed distal to the } \\
\text { wrist } \\
\text { Small delayed NAP recorded at wrist } \\
\text { when index finger stimulated }\end{array}$ \\
\hline 12 & Right median nerve lesion & $\begin{array}{l}\text { Motor conduction severely slowed } \\
\text { distal to the wrist }\end{array}$ \\
\hline
\end{tabular}
Unaffected Nerves

Normal NAPs recorded from right and left median and left ulnar nerve

Normal MCV in right median and ulnar nerves Normal NAPs recorded from right and left median and right ulnar nerve

Normal MCV and NAP recorded from left lateral popliteal nerve

Normal MCV in right ulnar nerve Normal NAP recorded from wrist when fifth finger stimulated

Normal MCV in right ulnar nerve Normal MCV and NAP recorded from right lateral popliteal nerve

$\mathrm{MCV}=$ motor conduction velocity $\quad \mathrm{NAP}=$ nerve action potential

ISOLATED PERIPHERAL NERVE LESIONS IN DIABETIC PATIENTS In diabetic patients with apparently isolated peripheral nerve lesions it may be asked whether the electrical abnormalities are also likely to be restricted to the clinically affected nerve, or whether more widespread changes may be found. We have investigated five such patients, two of them presenting with ulnar nerve lesions, two with median nerve lesions, and one with a lateral popliteal nerve lesion. While we did not attempt to study conduction in every accessible nerve of each patient, observations were made on 10 unaffected nerves, motor conduction being examined in six nerves and nerve action potentials in nine nerves. For all the unaffected nerves studied, results fell within the normal range (Table III).

In the large series of diabetic patients examined by Mulder et al. (1961) mean velocities for clinically unaffected nerves were significantly below the normal means. In our own patients the values for unaffected nerves also fell in the lower part of the normal range but the number of patients studied was too small for this to be statistically significant.
In the case of the clinically affected nerves, however, abnormalities of either motor velocity or of nerve action potentials were present in every case. Motor conduction was clearly abnormal in two, slightly abnormal in one, and normal in two. Nerve action potentials were reduced or absent in all four cases in which they were examined (Table III).

The relation between clinical and electrical findings is illustrated by the following case history:-

Case 8. Mr. M. L. (N.H. 87855), a storekeeper, was discovered to have diabetes in 1956 at the age of 51; his condition appeared to be satisfactorily controlled by diet alone. In June 1958 the patient fell on the outstretched right hand and four weeks later noticed that the hand was weak. This weakness gradually increased and at the time of the electrical examination in October 1959 severe wasting and weakness were present in the ulnar-supplied intrinsic muscles, without sensory loss. The clinical examination was complicated by the fact that the patient's right little finger had been amputated many years before, so that power in the hypothenar muscles could not be tested. However, in view of the presence of normal power in the forearm muscles and the absence of sensory

TABLE IV

MOTOR LATENCY AND CONDUCTION VELOCITY IN PATIENTS WITH ISOLATED PERIPHERAL NERVE LESIONS

\begin{tabular}{|c|c|c|c|c|}
\hline Case & Nerve & Muscle & $\begin{array}{l}\text { Latency } \\
\text { Wrist to Muscle (msec.) }\end{array}$ & $\begin{array}{l}\text { Conduction Velocity } \\
\text { Elbow to Wrist }(\mathrm{m} . / \mathrm{sec} .)\end{array}$ \\
\hline 8 & $\begin{array}{l}\text { Right ulnar } \\
\text { Right ulnar }\end{array}$ & $\begin{array}{l}\text { Abductor digiti minimi } \\
\text { First dorsal interosseous }\end{array}$ & $\begin{array}{l}4 \cdot 4 \\
6 \cdot 5\end{array}$ & $\begin{array}{l}43 \cdot 0 \\
37 \cdot 5\end{array}$ \\
\hline 11 & $\begin{array}{l}\text { Right ulnar } \\
\text { Right median }\end{array}$ & $\begin{array}{l}\text { Abductor digiti minimi } \\
\text { Abductor pollicis brevis }\end{array}$ & $\begin{array}{l}2 \cdot 9 \\
8 \cdot 3\end{array}$ & $\begin{array}{l}49 \cdot 2 \\
42 \cdot 5\end{array}$ \\
\hline 12 & $\begin{array}{l}\text { Right ulnar } \\
\text { Right median }\end{array}$ & $\begin{array}{l}\text { Abductor digiti minimi } \\
\text { Abductor pollicis brevis }\end{array}$ & $2 \cdot 7$ & $\begin{array}{l}52 \cdot 5 \\
40 \cdot 0\end{array}$ \\
\hline Normal range & $\begin{array}{l}\text { Ulnar' } \\
\text { Ulnar } \\
\text { Median }^{2}\end{array}$ & $\begin{array}{l}\text { Abductor digiti minimi } \\
\text { First dorsal interosseous } \\
\text { Abductor pollicis brevis }\end{array}$ & $\begin{array}{l}2 \cdot 0-3 \cdot 7 \\
3 \cdot 0-5 \cdot 0 \\
2 \cdot 9-5 \cdot 0\end{array}$ & $\begin{array}{l}49 \cdot 0-65 \cdot 6 \\
46 \cdot 2-66 \cdot 2 \\
48 \cdot 3-67 \cdot 9\end{array}$ \\
\hline
\end{tabular}

'From Gilliatt and Thomas (1960)

${ }^{2}$ From Thomas (1960) 


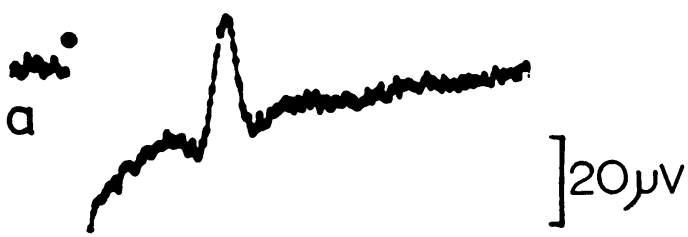

Median
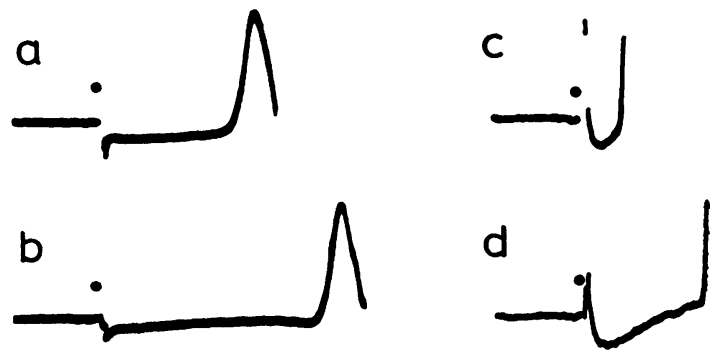

$2 \mathrm{msec}$
Ulnar

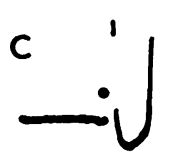

$2 \mathrm{msec}$

FIG. 3

FIG. 4

FIG. 3. Case 8. Tracings recorded from (a) the median nerve and (b) the ulnar nerve above the elbow with stimulation at the wrist. Stimulus at mark in each trace followed by nerve action potential in (a) but not in (b).

FIG. 4. Case 11. Records from the abductor pollicis brevis (a, b) and the abductor digiti minimi (c, d) taken at high amplification to show initial deflection of muscle action potentials with stimulation of median and ulnar nerves just above the wrist $(\mathrm{a}, \mathrm{c})$ and elbow $(\mathrm{b}, \mathrm{d})$. Stimulus at mark in each case.

loss, a local lesion of the ulnar nerve in the hand was suspected and ascribed to the patient's fall in June 1958.

The right ulnar nerve was stimulated just above the wrist and elbow, and muscle action potentials were recorded from the abductor digiti minimi and the first dorsal interosseous muscle; slight but uniform slowing of conduction was present throughout the length of nerve examined, values for the motor fibres to both muscles being just outside the normal range (Table IV). When the ulnar nerve was stimulated at the wrist no action potential was recorded from the nerve above the elbow (Fig. 3). For comparison the normal action potential recorded from the right median nerve at the elbow with stimulation at the wrist is also shown in Fig. 3. Nerve action potentials from the left median and ulnar nerves were also examined and were normal.

In this patient the median and ulnar nerves on both sides were examined and the conduction defect was confined to the right ulnar nerve. The electrical abnormality extended at least as high as the elbow and it is clear that it could not be explained by a local lesion in the hand as had originally been suggested on clinical grounds.

It is interesting that in all five patients with isolated lesions the nerves involved were those which are most commonly affected in non-diabetic subjects, and that in some of our patients a history of local trauma was obtained. For example, our patient with a lateral popliteal palsy (Case 10) had been crouching on the floor with the affected leg tucked under him, laying tiles in his house, during the week before he developed foot-drop. This type of history must raise the possibility that these were mechanical compressive lesions occurring in diabetic subjects who may or may not have had some predisposing abnormality of their peripheral nerves.

In the two patients with median neuropathy there was marked slowing of conduction in the segment of the median nerve distal to the wrist, velocity in the same fibres in the forearm being relatively normal. This combination of findings is most frequently encountered in the carpal tunnel syndrome (Simpson, 1956; Thomas, 1960), and for this reason both patients were treated by surgical division of the flexor retinaculum.

Case 11. Mrs. S. M. (M.H. K48246), a 52-year-old housewife, was admitted to the Middlesex Hospital in March 1959. For 15 years the patient had suffered from diabetes for which she took a small daily dose of insulin. In 1955 she began to experience attacks of painful tingling in the right hand which would wake her at night and which were relieved by hanging the arm out of bed. Subsequently, paraesthesiae also occurred during the day, and in the year before admission the patient also noticed wasting of the thenar muscles with difficulty in using the hand. Similar but less severe symptoms were present on the left.

Examination in March 1959 revealed severe wasting and weakness of the median-supplied thenar muscles on the right and mild wasting and weakness on the left. There was no evidence of abnormality outside the median territory. Sensation was normal except for a subjective change over the index, middle, and ring fingers of the right hand. Radiographs of the wrists were normal.

Motor conduction was examined in the right median 
and ulnar nerves. The results are shown in Table IV and illustrative tracings are shown in Fig. 4. It will be seen that there was marked slowing of conduction in the median nerve distal to the wrist, latency from wrist to muscle being $8.3 \mathrm{msec}$. (normal range $2.9-5.0 \mathrm{msec}$.). Conduction velocity in the median nerve in the forearm was only slightly reduced, and conduction in the ulnar nerve was normal. Nerve action potentials were also recorded at the wrist with stimulation of digital fibres in the fingers, as described by Gilliatt and Sears (1958). The potential recorded from the median nerve when the index finger was stimulated showed a small amplitude and an increased latency, whereas a normal potential was recorded from the ulnar nerve when the fifth finger was stimulated.

The electrical findings appeared to confirm the presence of a carpal tunnel syndrome and at operation on 19 March 1959 the flexor retinaculum on the right was divided under direct vision by Mr. R. D. Weeks. At the time of operation a sharply defined area of abnormal vascularity of the nerve, approximately $0.7 \mathrm{~cm}$. in length, was seen at the level of the distal margin of the retinaculum.

In spite of an apparently successful operation the patient continued to complain of weakness and discomfort in the hand. At a follow-up examination in June 1959 the right median nerve at the wrist was found to be electrically inexcitable. Although there was no response to nerve stimulation at the wrist, a few motor unit potentials in the abductor pollicis brevis were seen which were still under voluntary control, but by the time of the next follow-up examination in September 1959 even these were absent, the muscle showing the clinical and electrical appearances of complete denervation. There was also some increase in median sensory disturbance but otherwise the patient's clinical condition appeared to be unchanged.

Case 12. Mrs. R. F. (M.H. K52360), a 64-year-old housewife, was admitted to the Middlesex Hospital in July 1959. Diabetes had been discovered in 1942; it was first controlled by insulin and later by tolbutamide. In 1943 the patient had sustained a right Colles fracture. In 1957 she began to suffer attacks of numbness and tingling in the fingers of the right hand with a sensation of tightness of the hand on rising in the morning. In the following year wasting of the thenar muscles was noticed, together with difficulty in using the hand.

Examination in July 1959 revealed severe wasting and weakness of the right thenar muscles with subjective impairment of superficial sensation affecting the thumb and the index, middle, and ring fingers. There was no evidence of abnormality outside the median territory. Radiographs of the right wrist showed a mild deformity of the lower end of the radius attributable to her old Colles fracture, with secondary arthritic changes in the radiocarpal joint.

Motor conduction was studied in the right median and ulnar nerves. Results are shown in Table IV, from which it will be seen that there was marked slowing of conduction in the median nerve distal to the wrist (conduction time $25.6 \mathrm{msec}$.) with only slight slowing in the forearm (conduction velocity $40.0 \mathrm{~m}$./ $/ \mathrm{sec}$.). Conduction in the ulnar nerve was normal. At operation on 28 July 1959 the right flexor retinaculum was divided by $\mathrm{Mr}$. Valentine

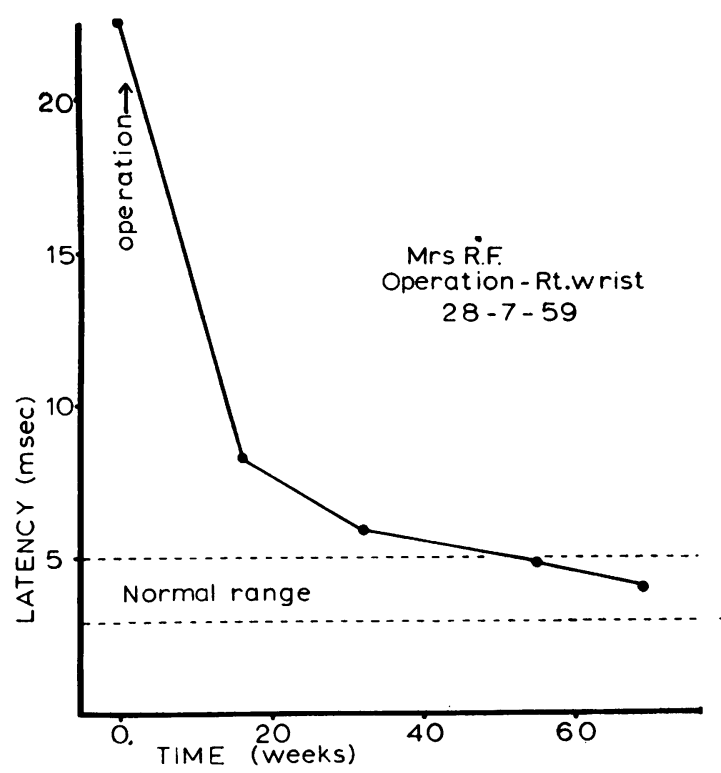

FIG. 5. Case 12. Latencies of muscle action potentials recorded from the abductor pollicis brevis with stimulation of the median nerve just above the wrist, before and after surgical division of the flexor retinaculum, to show postoperative recovery of normal latency.

Logue who observed that the median nerve was considerably swollen under the upper part of the ligament.

After operation median nerve conduction was reexamined at three-monthly intervals; the results are shown in Fig. 5, in which conduction time from wrist to muscle is plotted against the post-operative period in weeks. It can be seen that conduction time decreased progressively after operation and returned to the normal range at the end of one year.

Although mechanical factors may have determined the site of the lesion in Case 11, the response to surgery was quite unlike that seen in non-diabetic patients with the carpal tunnel syndrome, and the continued deterioration of median nerve function after operation must be attributed to her diabetes. This result cannot be attributed to inadequate surgery as an open operation was performed in which the flexor retinaculum was divided under direct vision. In Case 12 post-operative recovery was excellent and did not differ from that observed in non-diabetic patients after surgical decompression of the median nerve (Goodman and Gilliatt, 1961). Thus it appears that the lesion in this latter case was largely or wholly due to mechanical compression and that recovery was not impeded by the patient's diabetes. 
DISCUSSION

In our patients with sensory syndromes affecting the lower limbs an interesting parallel may be drawn between the changes in vibration sense and in nerve action potentials. On clinical examination loss of vibration sense in the feet was the only finding which was common to all five patients, and on electrical examination diminution or complete loss of the lateral popliteal nerve action potential was also present in every case. The appreciation of a tuning fork presumably depends upon synchronous conduction in a large number of fibres, so that impulses which start together at the periphery arrive simultaneously at the spinal cord. It may be suggested that vibration sense is lost when there is slowing and dispersion of impulses in individual fibres, so that bursts of activity in some fibres arrive at the spinal cord at a time when others are inactive, thus smoothing out the rhythmic pattern for the nerve trunk as a whole. The presence of a recordable nerve action potential also requires synchronous conduction in a number of fibres, and it is known that any slowing of conduction causes temporal dispersion of the potential (Gilliatt et al., 1961). This could occur without complete loss of conduction in any single fibre and would explain the reduction in vibration sense and in the size of the nerve action potential in one of our patients (Case2) who showed no other sensory change.

In our two patients with mixed motor and sensory neuropathy, asymmetrical muscle wasting and weakness were the most conspicuous features and proximal muscles were severely involved. The clinical picture thus resembled the diabetic amyotrophy described by Garland (1955), and one of our patients (Case 7) was subsequently examined by Dr. Garland, who accepted this diagnosis. The marked slowing of motor nerve conduction found in both patients is therefore of particular interest. Slowing of this degree is characteristic of peripheral neuropathy and does not occur in patients with muscle wasting due to spinal cord disease (Henriksen, 1956). The increased latency of the knee jerk in Case 7 is also characteristic of neuropathy, and comparable increases in latency have not been found in patients with wasting of the quadriceps due to anterior horn cell lesions such as anterior poliomyelitis or motor neurone disease (Gilliatt, Lange, and Willison, unpublished observations). It therefore seems reasonable to suggest that the amyotrophy of Garland is in fact a motor neuropathy with a particular tendency to affect proximal muscles. It should be remembered, however, that extensor plantar responses were present in some of Garland's patients, and in view of this finding a combination of spinal and peripheral changes must be postulated.
In our patients with isolated peripheral nerve lesions the correlation between clinical and electrical abnormalities was closer than in other published series. This difference may be related to the method of study. Mulder et al. (1961) and Skillman et al. (1961) examined large numbers of unselected diabetic patients whereas we have carried out a more detailed investigation of a small group. Furthermore, we have been able to examine nerve action potentials whereas the other series are concerned only with motor conduction velocity. In relation to our findings in two patients with the carpal tunnel syndrome it is interesting that Mulder et al. found delayed conduction in the median nerve distal to the wrist in nine out of a total of 103 unselected diabetic patients, which suggests that there may be an increased incidence of the carpal tunnel syndrome in diabetes. From their results and from our own it is clear that mechanical factors are of considerable importance in the aetiology of isolated peripheral nerve lesions occurring in diabetic patients.

When considering changes in nerve conduction of the type described in this paper it must be emphasized that only large myelinated fibres have been examined. Until new techniques have been evolved for the study of small myelinated and non-myelinated fibres, our picture of peripheral nerve function is necessarily incomplete. From what is already known of autonomic disturbances in diabetes (Martin, 1953; Sharpey-Schafer and Taylor, 1960) it is clear that the study of conduction in small fibres represents an important field for investigation in the future.

\section{SUMMARY}

Peripheral nerve conduction has been studied in 12 patients with diabetic neuropathy. In five patients with predominantly sensory neuropathy affecting the lower limbs, diminution or loss of lateral popliteal nerve action potentials was the most constant finding. In two patients with mixed motor and sensory neuropathy marked slowing of motor nerve conduction velocity was found, and in one of them the latency of the knee jerk was substantially increased. When five patients with isolated peripheral nerve lesions were studied, electrical abnormalities were found only in the clinically affected nerves.

We wish to thank members of the staff of the Middlesex Hospital and of the National Hospital who have referred patients for investigation. We are grateful to Dr. Hugh Garland for his help with Case 7.

Grants towards the cost of the apparatus were made by the Medical Research Council and the Mary Kinross Charitable Trust, and we also gratefully acknowledge the provision of facilities by the Clinical Research Committee of the Middlesex Hospital. 


\section{REFERENCES}

Bergamini, V., and Sibour, F. (1960). Riv. Patol. nerv. ment., 81, 415.

Ferrari-Forcade, A., Temesio, P., and Gomensoro, J. B. (1960). Acta neurol lat.-amer., 6, 43.

Garland, H. (1955). Brit. med. J., 2, 1287.

Gilliatt, R. W., Goodman, H. V., and Willison, R. G. (1961). J. Neurol. Neurosurg. Psychiat., 24, 305.

and Sears, T. A. (1958). Ibid., 21, 109.

and Thomas, P. K. (1960). Ibid., 23, 312

Goodman, H. V., and Gilliatt, R. W. (1961). Ann. phys. Med., 6, 137.
Henriksen, J. D. (1956). M.S. Thesis. University of Minnesota.

Malcolm, D. S. (1951). J. Neurol. Neurosurg. Psychiat., 14, 15.

Martin, M. M. (1953). Lancet, 1, 560.

Mulder, D. W., Lambert, E. H., Bastron, J. A., and Sprague, R. G. (1961). Neurology, 11, 275.

Sharpey-Schafer, E. P., and Taylor, P. J. (1960). Lancet, 1, 559.

Simpson, J. A. (1956). J. Neurol. Neurosurg. Psychiat., 19, 275.

Skillman, T. G., Johnson, E. W., Hamwi, G. J., and Driskill, H. J. (1961). Diabetes, 10, 46.

Thomas, P. K. (1960). Neurology, 10, 1045.

Sears, T. A., and Gilliatt, R. W. (1959). J. Neurol. Neurosurg. Psychiat., 22, 175. 